\title{
Federici, Silvia (2018): El patriarcado del Salario. Críticas feministas al marxismo. Madrid: Traficantes de Sueños, 122 pp. ISBN: 978-84- 948068-3-4.
}

El Patriarcado del salario no sólo es una lectura necesaria para evaluar el rol de la mujer como eje vertebrador de la reproducción de la mano de obra, sino que nos adentra en una de las yuxtaposiciones teóricas más debatidas tanto dentro como fuera del pensamiento crítico feminista: marxismo y feminismo. Silvia Federici reflexiona en su obra sobre el concepto de reproducción, no como un opuesto al de producción -tal y como recoge Marx en El Capital- sino como un complemento fundamental a la hora de entender las relaciones de clase, de explotación y dominación que articulan la totalidad del proletariado, independientemente del género, la edad y la raza.

Asimismo, esta obra realiza una serie de interrogantes metodológicos e historiográficos: ¿Cómo se relacionan feminismo y marxismo? ¿Cuál es el vínculo entre patriarcado y capitalismo? ¿Qué relación existe entre la lucha por la liberación de la mujer y la lucha de clases?

El patriarcado del salario profundiza en los esquemas marxistas con un profundo espíritu crítico, reformulando y ampliando el horizonte de los mismos. Federici subraya cinco tesis que el feminismo puede utilizar y que son elementales para el análisis de la explotación de la mujer y la posición que ésta ocupa dentro del sistema capitalista. En este sentido, veremos cómo es necesario volver a recuperar la tesis de la lucha de clases como motor de la historia, la naturaleza humana a modo de producto de las relaciones sociales en procesos continuos de cambio, las teorías como dispositivos para cambiar las realidades, el trabajo humano como fuente de riqueza y el análisis sistémico del capitalismo.

Federici resume estos postulados comprendiendo que "al descubrir la centralidad del trabajo reproductivo para la acumulación capitalista, también surgió la pregunta de cómo sería la historia del desarrollo del capitalismo si en lugar de contarla desde el punto de vista del proletariado asalariado se contase desde las cocinas y dormitorios en los que, día a día y generación tras generación, se produce la fuerza de trabajo" (Federici, 2018: 65). ¿Habría cambiado algo si El Capital hubiese sido escrito por una mujer? Nos cuestionamos tras la lectura de la anterior reflexión, una reflexión bastante candente en la crítica al feminismo contemporáneo. Federici consigue responder a esta pregunta alumbrando espacios a los que la teoría marxista no ha llegado, en particular el papel de la mujer como dadora de vida y, por tanto, de mano de obra.

Al igual que sucede en otros textos de la autora, como El Caliban y la bruja, la revisión histórica es clave, rompiendo con el manido discurso naturalista en torno al concepto de feminidad. En este sentido, Federici analiza el inicio del capitalismo industrial en Gran
Bretaña y propone que al contrario de lo que la historiografía venía afirmando, la prototípica familia proletaria no se consolidó hasta la segunda mitad del siglo XIX.

Para comprender el proceso de constitución de esta nueva tipología de núcleo familiar, es necesario atender a las particularidades del contexto histórico de finales del siglo XVIII y principios del XIX, cuando la mano de obra en las fábricas estaba constituida por mujeres, hombres y niños que realizaban su trabajo en condiciones infrahumanas, lo cual reducía su esperanza de vida drásticamente. Es este un entorno donde surgen las protestas y las huelgas que se suman a otros reclamos como los problemas generados por la industria en términos de productividad, las condiciones de los trabajadores $y$, consecuentemente, las dificultades para llevar a buen puerto su reproducción. Este cúmulo de circunstancias provocó que el estado interviniera regulando el empleo asalariado en busca de un tipo de trabajo más fuerte y productivo. En este sentido, los problemas sobre la escasez de la mano de obra y el merme de la tasa de natalidad y fecundidad fueron achacados a la ausencia de la figura de la ama de casa.

Federici señala en este punto que lo que se jugó en el seno de las legislaciones proteccionistas fue algo más que una mera reforma del trabajo fabril, sino la instrumentalización de la producción y reproducción de las mujeres. Reducir las horas de trabajo de las mujeres fue el inicio hacia una nueva estrategia de clase, reasignando las mujeres al proletariado del hogar. Un rol, el de la mujer devuelta al entorno familiar, cuyos intereses se focalizaban en la producción de trabajadores en vez de mercancías físicas.

A continuación, la autora expone las variables que desembocaron en el nuevo núcleo familiar que relegaba a la mujer a un espacio nutricio, no asalariado, con el fin último de producir y reproducir la mano de obra. La asignación de un salario al obrero dejando impagada la jornada del trabajo doméstico creó unas relaciones de poder, dominación y violencia que acentuaron la creciente invisibilidad de la mujer. Federici llama es este fenómeno el patriarcado del salario. Proceso que se convierte en hegemónico y universalista, naturalizando los roles del trabajador asalariado -relacionado con lo masculino- y régimen de cuidados nutricios impagados -asociado a lo femenino-.

La obra avanza a los años setenta y la crisis del modelo familiar anteriormente expuesto. La incorporación de la mujer al mercado laboral asalariado y la accesibilidad a los sistemas de formación educativa y profesional especializada actualizó la paradoja planteada por Marx en torno a la igualdad de género en las relaciones capitalistas. Federicci ataca esta tesis: el 
trabajo asalariado no libera a la mujer per-se, pues al incorporarse al mundo laboral remunerado, el trabajo reproductivo no desaparece, sino que se suma al otro, generando una doble imposición: la capital y la reproductiva. Según la autora, este cambio no se llevaría a cabo desde cero, sino que resulta de un proceso histórico concreto basado en la intencionada necesidad de la devaluación de la mano de obra. De esta forma, el rol femenino comienza a asociarse a las tareas nutricias, por lo que la mayor parte de los puestos de trabajo ofertados se encaminan a los cuidados y lo doméstico.

Este enfoque lo usa Federici para criticar las tesis progresistas que atribuyen a la tecnología el desarrollo de la mejora de las condiciones de vida en los espacios del trabajo reproductivo y productivo. En su crítica descarta la posibilidad de que el trabajo de cuidados sea sustituido por el trabajo que pueda generar una máquina inteligente -robots, sistemas de inteligencia artificia, domótica, etc.,-- A este tipo de tecnologías las denomina nursebots. En el caso que se llegara a dar la sustitución de las nursebots por la mano de obra de la mujer la sociedad debería plantearse cuál sería la repercusión que esto supondría en la psique humana y en la construcción de la subjetividad. Al eliminarse el plano afectivo en esos procesos sumamente importantes en el desarrollo de las personas socialización e infancia, gerontología y bienestar, etc.,podríamos caer en un determinismo tecnológico de resultados catastróficos para el pleno desarrollo social de los sujetos. La sustitución del humano por lo maquinico se complica en los espacios de lo doméstico no remunerado, no se atisba como una posibilidad a corto y medio tiempo. Asimismo, la rentabilidad mermaría, pues se trata de trabajos domésticos no remunerados. Tristemente no es la lógica del pleno desarrollo de la sociabilidad emocional lo que prima, sino el capital que se ahorra.

Las respuestas que aportó la autora en la década de los setenta giraban en torno a la defensa de un salario justo y ético para el trabajo doméstico. Objetivo que pretendía visibilizar la labor oculta de las mujeres a favor de su empoderamiento. Respuestas contrarias a las tesis marxistas que veían en el desarrollo de las fuerzas productivas la oportunidad para conseguir la igualdad entre hombres y mujeres. Posturas, las marxistas, que con el tiempo han resultado erróneas. Lo expuesto hasta ahora por la autora se aleja por completo de los dogmas marxistas siendo su principal desacuerdo el hecho de que marxismo continúe enfatizando el capital obrero como única fuerza de combate posible, ignorando otras luchas como son las feministas, las raciales o las ecologistas.

En definitiva, esta obra constituye un referente actual en los estudios feministas y de género, ofreciendo herramientas clave para desnaturalizar la división sexual del trabajo y las identidades derivadas. Asimismo, la autora rompe con el determinismo cultural sobre la construcción del concepto de género. La clave de su construcción no sólo radica en la cultura sino en el cambio y en su carga política, de ahí que siempre esté en una continua definición. El patriarcado del salario.
Críticas feministas al marxismo es una obra esclarecedora y necesaria que nos permite comprender de forma profunda e históricamente situada los debates $y$ procesos sobre las diferencias entre hombres $y$ mujeres en una sociedad altamente capitalizada como la contemporánea.

Ana Amigo Requejo

(D) https://orcid.org/0000-0001-9787-5054 Universidad Complutense de Madrid, España ana.amigo@ucm.es

Recibida: 01-04-2018 Aceptada: 09-04-2018

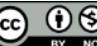

